\title{
HIGH FLUX FILM AND TRANSITION BOILING
}

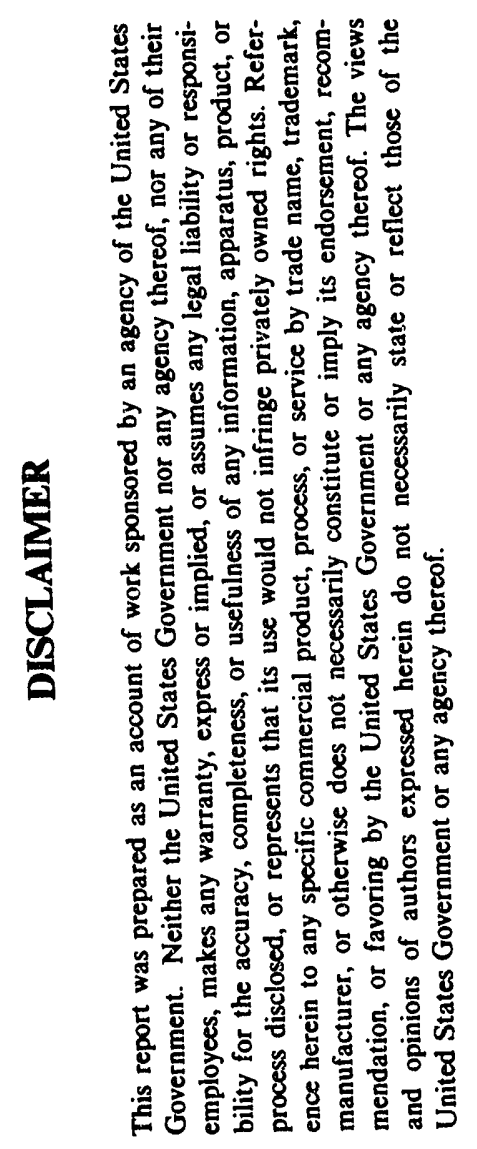

Final Report

DOE/ER/13893-1 (Final)

UH Budget 1-5-53756

April, 1988 - January, 1993

Larry C. Witte

Department of Mechanical Engineering

University of Houston

Houston, TX

77204-4792

February, 1993

$\mathrm{OS}_{\mathrm{i}}$

PREPARED FOR THE U.S. DEPARTMENT OF ENERGY UNDER GRANT DE-FGO5-88ER13893 


\section{INTRODUCTION}

'In this research we have carried out an investigation testing the potential for altering the boiling curve through the effects of high velocity and high subcooling. A major part of the project was to develop an apparatus with which we could perform experiments using water and Freon-113 flowing over cylindrical electrical heaters in crossflow to see how velocity and subcooling affect the boiling curve, especially the film and transition boiling regions. We sought subcooling levels down to near the freezing points of these two liquids to prove the concept that the critical heat flux and the minimum heat flux could be brought together, thereby averting the transition region altogether. A second emphasis of the study was to gain insight into how the various boiling regions could be represented mathematically on various parts of the heating surface.

The motivation for the research grew out of a realization that the effects of very high subcooling and velocity might be to avert the transition boiling altogether so that the unstable part of the boiling curve would not limit the application of high flux devices to temperatures less than the burnout temperatures. However, before this project there had been no systematic investigation of such behavior. In the sections that follow, summaries of results from the study are described. It shows that the potential for averting the transition region is good, and points the way to further research that is needed to demonstrate the potential. Only brief summaries are given, broken down into categories -Experimental Measurements and Observations, Theory and Analysis, and Complementary Studies. The reader is referred to copies of papers that are appended to the report for details of our results.

\section{EXPERIMENTAL MEASUREMENTS AND OBSERVATIONS}

The experimental flow loop that was developed for these studies is described in Sankaran and Witte ( 990) in Appendix 1. Basically, it consisted of a thin-walled electrically-heated cylinder contained in the test section of a flow loop capable of circulating a wide variety of working fluids. The fluids chosen for experimentation in these studies was Freon-113 and water. Freon-113 allowed data to be obtained over all regions of boiling -- nucleate, film and transition. With water, only data in the nucleate boiling regime to near the critical heat flux could be obtained.

\section{Visual Observations of the Boiling Phenomena}

A very important part of this study was to determine the flow patterns that occur when various boiling regions are encountered. This information can be used to gain insight into how the processes might be modelled. In addition to naked eye observations, a Spin 
Physics SP-2000 Motion Analyzer System was used for motion picture analysis while a Nikon still camera was used to capture various flow region information.

At very high subcoolings not much net vapor is produced around the heater, regardless of the boiling region. Bubbles quickly condense as they move away from the hot surface, while vapor film regions that occur during film boiling are kept very thin by the influence of subcooling.

TABLE 1

RANGE OF OPERATING CONDITIONS

FREON-113

\begin{tabular}{|c|c|c|c|}
\hline Set No. & Velocity & $\underline{T}_{\text {sat }}$ & Subcooling \\
\hline 1 & $2.95 \mathrm{~m} / \mathrm{sec}$ & $60.0 \mathrm{C}$ & $50.0 \mathrm{C}$ \\
\hline 2 & 2.95 & 61.0 & 51.0 \\
\hline 3 & 2.95 & 59.5 & 54.5 \\
\hline 4 & 3.53 & 65.5 & 58.6 \\
\hline 5 & 3.81 & 68.1 & 57.6 \\
\hline 6 & 3.53 & 65.5 & 57.0 \\
\hline 7 & 2.95 & 60.0 & 56.5 \\
\hline 8 & 2.95 & 60.0 & 55.6 \\
\hline 9 & 2.95 & 59.5 & 49.3 \\
\hline 10 & 2.95 & 61.0 & 42.0 \\
\hline
\end{tabular}

At low heat fluxes, no boiling was present and non-boiling forced convection correlations compared well with the experimental data. As the heat flux was increased and the surface temperatures increased well beyond the local saturation temperatures, nucleate boiling ensued. Bubbles were observed being formed on the surface and being swept around the periphery of the heater. A wake was formed, but it was a wake that consisted primarily of liquid rather than primarily of vapor as is the case for nearly saturated boiling.,

The first appearance of film boiling on the heater was somewhat random; in some cases it began on the ends of the heater and in other cases a small film boiling patch developed on the top of the cylinder. As heat flux was increased slightly, film boiling would begin on the top of the cylinder near the ends. These film boiling patches increased in size as heat flux was increased, eventually covering the entire heater surface, top and bottom. It was clear that even for the conditions of high subcooling encountered in these 
experiments, film and nucieate boiling could coexist on the heater surface. The:e regions were separated by transition "fronts" which took on a significantly different appearance than nucleate or film boiling. The region near the front was characterized by the production of many small bubbles that were rapidly diffused into the surrounding liquid.

Film boiling for all these high velocity, high subcooling experiments showed a much thinner wake than the nucleate boiling wake. An oscillating separation line was observed slightly past the 90 -degree point on the heater.

Once film boiling was established and the heat flux was decreased slowly, the vapor film would begin to collapse on the bottom of the heater which was colder than the top which was covered by the wake. The collapse was characterized by the disappearance of the liquid-vapor interface at the lower stagnation point of the heater. A transition front as described previously separated film from nucleate boiling, and it was characterized by accentuated bubble activity as described before. The situation of film bciling on the top of the heater and nucleate boiling on the bottom was highly stable and could be (and was) maintained for several hours in some experiments. As heat flux was decreased further the film boiling on the top of the heater collapsed in a patchy manner leading to complete nucleate boiling on the heater.

\section{Temperature Measurements}

It is logical to assume that the bottom of the heater should always be colder than the top of the heater because the cold liquid comes into contact with the heater at the lower stagnation point, and a thermal boundary layer of sorts develops as the liquid moves around the heater. While in general this was always the case for both film and nucleate boiling, some unexpected behavior of the temperatures was observed.

The heater was equipped with thermocouples that could measure the temperature at the bottom stagnation point, the upper stagnation point and the 90-degree point around the heater. The top and bottom thermocouples behaved differently as the subcooling was varied for a given velocity. At the highest subcooling level, $57 \mathrm{C}$ for Freon-113 the bottom and middle thermocouples showed an unexpected decrease in temperature as the peak heat flux was approached. Such a decrease obviously means that the heat transfer coefficient over that thermocouple location must have increased dramatically with heat flux because of the constant heat flux condition at the surface. This could be explained by a dramatic increase in the population of bubbles at this transition point. However, as stated in the previous section, there was no visual evidence that such an increase in the bubble density occured at these transition points. Many tests for repeatabiity of this temperature behavior were made to insure the integrity of the measurement system. In all cases the data were repeatable. Such behavior has been observed in other electrically-heated nucleate boiling 
systems, and is attributed to the suppression of nucleate boiling up to wall temperatures typical of well-developed nucleate boiling, followed by a sudden onset of nucleate boiling as heat flux is increased. It is possible that such a phenomenon is occuring in our experiments but the population of bubbles at the conditions of very high subcooling is so small that changes are visually undetectable.

Azimuthal temperature differences were more pronounced in the film boiling region than in the nucleate boiling region. In film boiling, the top could be more than $115 \mathrm{C}$ hotter than the bottom of the heater. Extensive experiments were carried out at $2.95 \mathrm{~m} / \mathrm{sec}$ at different subcooling levels, and the effect of velocity was measured at a subcooling of 58 C, see Sankaran and Witte (1990).

Near $\mathrm{q}_{\min }$, the temperature differences between the top and bottom decreased. As the heat flux was decreased slowly, the vapor film collapsed on the bottom and filın boiling prevailed at the top as described previously. Thus, at the top the temperatures remained high typical of film boiling, while the bottom and center did not immediately fall all the way into the range typical of nucleate boiling. Rather, the temperatures arranged themselves in decreasing temperature from hottest at the top to coldest at the bottom. Thus we observed discontinuities in the bottom and middle thermocouple readings prior to the entire surface being enveloped in nucleate boiling. The simultaneous existence of film and nucleate boiling on the surface affects the temperature that can exist at the bottom and middle thermocouples locations even though it is clear that film boiling no longer exists over those thermocouple locations. The middle thermocouple reads a higher temperaturc inan the bottom one because it is closer to the film boiling patch at the top of the heater.

The existence of different regions of boiling in close proximity on a surface can produce discontinuities in temperature at a particular location as the heater goes through the process of transition from film to nucleate boiling. And these are not unstable points because tests for repeatability show that these points can created either by increasing or decreasing the heat flux.

Whether or not these intermediate temperature points represent a form of transition boiling or true nucleate boiling could not be ascertained from our visual observations, and remains to be investigated.

\section{The Relationship of $q_{\max }$ to $q_{\min }$}

For Freon-113 we could find the ratio of $q_{\min }$ to $q_{\max }$ is terms of subcooling for various velocities. Our measurements showed it is clear that subcooling has a dramatic effect in this regard, as our data clearly show the trend toward unity as subcooling is increased. We were able to bring the $\mathrm{q}_{\min }$ to $\mathrm{q}_{\max }$ ratio to $77 \%$ for highly subcooled 
Freon-113. Although our experiments did not cover a wide range of velocities, it is clear that subcooling has a much more profound influence on the ratio of $q_{\min }$ to $q_{\max }$ than does valocity.

\section{Nucleate Boiling of Highly Subcooled Water}

Steady state film boiling could not be maintained with water at the subcoolings of interest in our research. Four heater assemblies were destroyed (burnt out) because of the very high temperacures attained as film boiling ensued. The highest steady state nucleate boiling heat flux attained was $11.6 \mathrm{MW} / \mathrm{m}^{2}$, with $17.8 \mathrm{~kW}$ (897 amps at 19.88 volts) of power dissipation in the heater. The heater surface temperatures were around $300 \mathrm{C}$, and upon further increase in heat flux, the heater was destroyed.

The data demonstrate the same type of behavior as Freon-113, with the temperature overshoot existing for the thermocouples on the lower parts of the heater. Upon decreasing the heat flux in contrast to increasing it, a hysteresis occurs. This is very similar to what happens in pool boiling systems.

It is clear that water and Freon-113 demonstrate similar behavior in the nucleate boiling region even though the heat fluxes in water are at least an order of magnitude higher than for Freon-113. However, the inability of the apparatus to achieve film boiling without burnout prevented the determination of the ratio of $q_{\min }$ to $q_{\max }$ for highly subcooled water.

Research is continuing in this general area under other sponsorship. The flow loop and test section has been re-designed to withstand several atmospheres of pressure. In this way subcooling can be extended significantly even though the chiller is operating at its capacity.

\section{THEORY AND ANALYSIS}

A full solution of the momentum and energy equations for the case of flow film boiling heat transfer from cylinders in highly subcooled liquids was performed in this study. We wanted to sort out the influence of subcooling and velocity both on the front part of the heater, over which a smooth vapor film is formed, and in the wake region, where a vapor wake is over-ridden by a re-circulating liquid wake region. We took advantage of the fact that the vapor wake region appears to behave much like a flat plate in pool boiling rather than a forced convection problem. The details of this development are included in Chou and Witte (1992), and the PhD dissertation of Chou (1992).

A boundary-layer-like solution was obtained over the front part of the heater up to the point where the vapor layer separated from the surface to form a vapor wake. The equations included the effects of radiation, variable physical properties of the vapor, 
buoyancy, inertia and convection in the liquid and vapor regions. A rigorous local similarity transformation allowed the equations to be solved numerically over the front part of the heater. The influence of liquid subcooling, velocity and other pertineni parameters were found for specific fluids and configurations, as well as in non-dimensional terms. The separation points were also predicted by this technique.

The wake was treated as if there were axisymmetric "domes" of vapor sitting at the top of the heater rather than a fully three dimensional structure. An effective radius was developed that insured that the flow area for vapor into the wake and the area for heat transfer from the heater were preserved in the transformed geometry. A simplified convection analysis predicted the shape of the vapor dome and its dimensions. Knowing this, and the temperature fields, the heat flux could be calculated.

The two solutions, front and wake, had to match at the separation point. The film thicknesses, temperatures, pressures, etc. formed a set of constraints that had to be met.

A comparison of the results to the data of Sankaran (1991) showed that this analysis predicts highly subcooled data extremely well. No other solution is available that is as complete as this one. Indeed, the higher the subcooling, the better is the agreement between the theory and data.

The solution was used to investigate the influence of various parameters on the heat transfer from the heater. It was found that for high subcooling levels the variable properties of the vapor affect the predicted heat transfer significantly, up to $20 \%$ higher than a constant property solution evaluated at the vapor film temperature. For Freon-113, it was found that a Nusselt number correction, $\mathrm{Nu}=\mathrm{Nu}_{\mathrm{o}}\left(\mathrm{T}_{\mathrm{w}} / \mathrm{T}_{\mathrm{f}}\right)^{\mathrm{n}}$, predicts experimental data quite well. Thus, a full solution with variable properties is probably not needed. In the equation, $\mathrm{Nu}_{\mathrm{O}}$ is the Nusselt number for the constant property solution, and $\mathrm{w}$ and $\mathrm{f}$ refer to wall and film properties respectively. The exponent $n$ depends upon the prevailing conditions. We found it to be 0.24 for highly subcooled Freon-113. We are continuing to test this technique for other fluids and operating ranges to see how universal it might be as an extension of Chou's dissertation.

\section{COMPLEMENTARY STUDIES}

During the period of the study, Prof. M. Shoji of the University of Tokyo and Prof. M. Poniewski of the Univeristy of Kielce (Poland) visited in our laboratory. They studied various aspects of film and transition boiling that were not directly covered by this grant but provided insight into the mechanisms of film and transition boiling. The graduate stuáents and the principal investigator supported by the grant aided in this research. Appendix 1 contains copies of papers that resulted from this collaboration. 


\section{LIST OF PUBLICATIONS BASED ON GRANT RESEARCH}

S. Sankaran, Highly Subcooled Flow Boiling from a Cylinder in Cross-flow, PhD Dissertation, University of Houston, May, 1990.

X.S. Chou, Flow Film Boiling across a Horizontal Cylinder, PhD Dissertation, University of Houston, December, 1992.

Pool Boiling on a Large Horizontal Flat Resistance Heater, with R. Reguillot, J.H. Lienhard, and M. Poniewski, AIAA Paper No. 92-4052, presented at the National Heat Transfer Conference, San Diego, August, 1992.

A Theoretical Model for Flow Film Boiling Across Horizontal Cylinders, with X.S. Chou, AIAA Paper No. 92-4051, presented at the National Heat Transfer Conference, San Diego, August 1992.

A Complete Theoretical Model for Flow Film Boiling Across Horizontal Cylinders, with X.S. Chou, Proceedings of the Engineering Foundation Conference on Pool and External Flow Boiling, Santa Barbara, California, March, 1992, pp.325-330.

Measurement of Liquid-Solid Contact Using Micro-Thermocouples in Pool Transition Boiling of Water on a Horizontal Copper Surface, with M. Shoji, S. Yokoya, M. Kawakami, and H. Kuroki, Proceedings of the JSME/ASME Joint Thermal Engineering Conference, Reno, Nevada, March 1991, Vol. 2, pp. 333-340.

Highly Subcooled Flow Boiling of Freon-113 and Water Over Cylinders, with S. Sankaran, Proceedings of the JSME/ASME Joint Thermal Engineering Conference, Reno, Nevada, March 1991, Vol. 2, pp. 3-9.

Liquid-Solid Contact and Effects of Surface Roughness and Wettability in Film and Transition Boiling on a Horizontal Large Surface, with M. Shoji, S. Yokoya, and M. Ohshima, proceedings of the 9th International Heat Transfer Conference, Jerusalem, August 1990; G. Hetsroni, editor, Hemisphere Press, pp. 135-140.

Highly Subcooled Flow Boiling of Freon-113 Over Cylinders, with S. Sankaran, presented at the AIAA/ASME Heat Transfer and Thermophysics Conference, Seattle, Washington, June 1990; ASME Heat Transfer Division Vol. 136, pp. 29-34.

The Influence of Surface Conditions and Subcooling on Film/Traitsition Boiling, with M. Shoji and S. Sankaran, Experimental Thermal and Fluid Sciences, 1990, Vol. 3, pp. 280-290.

The Effect of Liquid Subcooling and Surface Conditions on Film/Transition Boiling, with M. Shoji, K. Chang, and S. Sankaran, Proceedings of the International Symposium on Phase Change Heat Transfer, Chongqing, Peoples Republic of China, May 1988, pp. 117-122.

The Effect of Liquid Subcooling and Surface Roughness of Film/Transition Boiling, with M. Shoji and S. Sankaran, proceedings of the 1988 National Heat Transfer Conference, Houston, Texas; ASME-Heat Transfer Division Vol. 96, No. 2, pp. 667673.

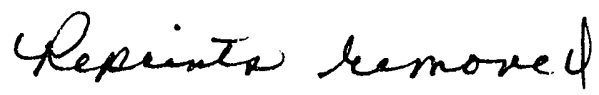



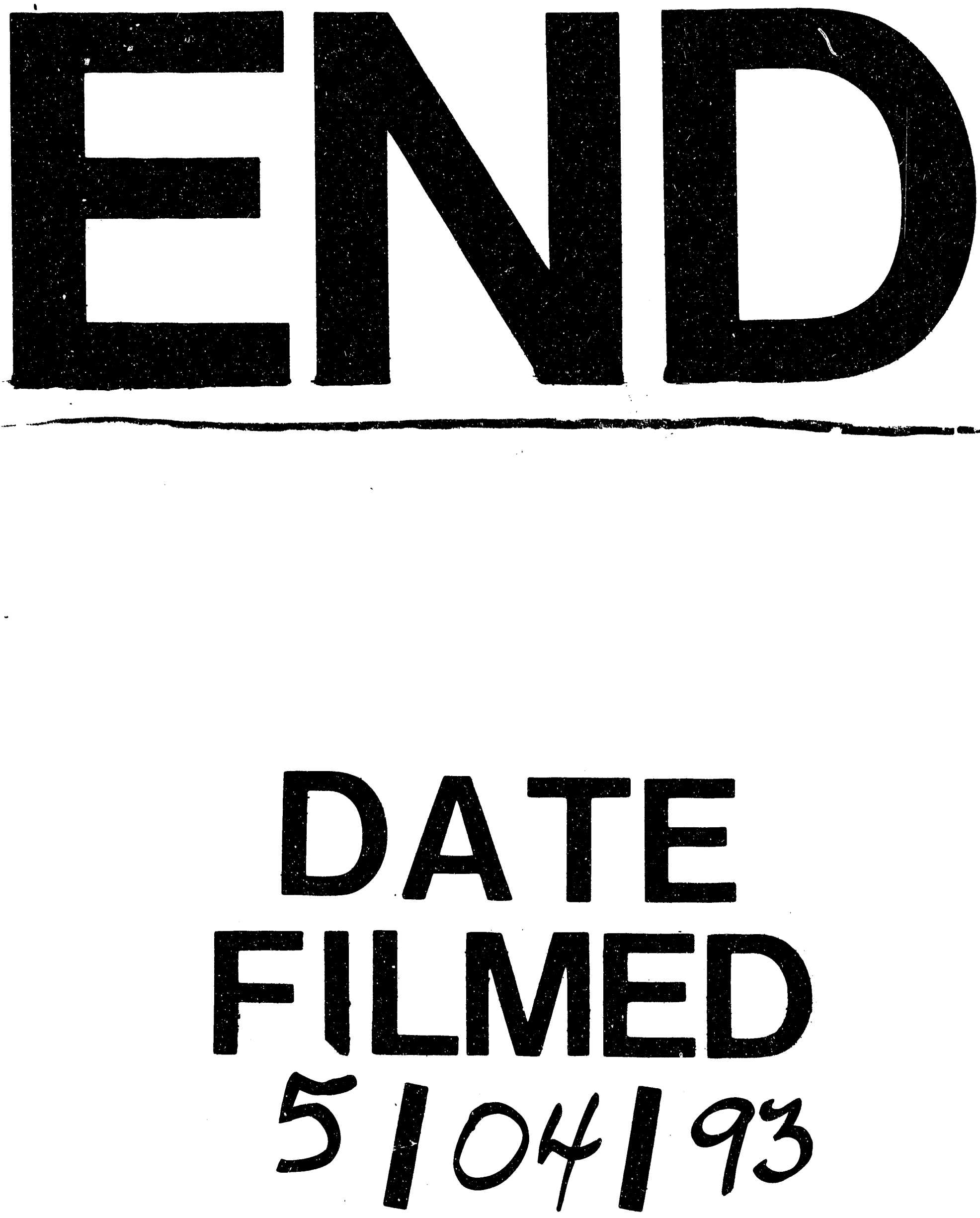
